\title{
A New Round of Policy Research on Counterpart Assistance to Xinjiang: Policy Text Analysis Perspective
}

\author{
Kan Yongle ${ }^{1, a}$, Li Zhicui ${ }^{2, b}$ \\ ${ }^{1}$ Xinjiang Normal University Business School, Urumchi, Xinjiang, China \\ ${ }^{2}$ Xinjiang Normal University Business School, Urumchi, Xinjiang, China \\ a237477023@qq.com \\ b328260968@qq.com
}

\begin{abstract}
As a national strategy, the new round of counterpart assistance policy has injected vitality into the development of Xinjiang in the new era and promoted social progress and improvement of people's livelihood in Xinjiang. Through the analysis of the form and content characteristics of the policy text since the implementation of the new round of counterpart assistance work, the results show that the new round of counterpart aid to Xinjiang is a comprehensive aid that pays equal attention to blood transfusion and hematopoiesis, but there are also some problems, such as incomplete content and weak operability. Therefore, it is necessary to improve the systematicness and effectiveness of aid policies to Xinjiang.
\end{abstract}

Keywords: a new round of counterpart assistance to Xinjiang, policy, text analysis

\section{INTRODUCTION}

Since the start of the new round of counterpart assistance to Xinjiang, with the help of the central and state organs, as well as 19 provinces and cities, the comprehensive assistance to the border has been fully implemented in the form of industry, cadres, talents, science and technology, education and so on ${ }^{[1]}$ Xinjiang has achieved remarkable results in the development of various undertakings. As an important work to promote Xinjiang's reform and development, social progress and improvement of people's livelihood, the central government has continuously increased its support for Xinjiang, and continuously improved the comprehensive benefits of its counterpart assistance to Xinjiang. In the course of practice, more scholars have studied the new round of aid policy, including the implementation status quo, policy effect evaluation, path selection, etc, which provide academic support for the new round of counterpart assistance to Xinjiang, but less research from the perspective of policy text analysis. From the point of view of policy text analysis, this paper takes the new round of counterpart aid policy text since 2010 as the research object, adopts the combination of quantitative and content analysis method, analyzes the evolution characteristics and focus direction of the work of aiding Xinjiang, and provides corresponding reference for further exerting the positive effect of the policy of aiding Xinjiang.

\section{RESEARCH DESIGN}

Policy literature can reflect the change and diversity of social processes, and is the result of the comprehensive influence of social economy, politics and culture in a certain field ${ }^{[2]}$.It is a mature method to study the policy and related issues through text analysis, but the content of this paper is less for the new round of counterpart aid policy in Xinjiang. This paper focuses on the policy text related to the aid to Xinjiang issued by China from 2010 to 2019 since the implementation of the new round of counterpart aid to Xinjiang. The main ways to obtain policies are government websites such as the Chinese government network, the State Council, the National Development and Reform Commission, the China Knowledge Network and the Peking University Magic 
Database. The search method is based on the connotation of the new round of counterpart aid policy, with aid to Xinjiang, counterpart support Xinjiang and so on as the search term, the policy for all-round search. Through screening, the relevant policy texts of aid to Xinjiang after 2010 are extracted from the search results. At the same time, in order to ensure the accuracy and representativeness of the data, the selection of policy texts need to follow the following criteria: First, the content of the policy should be closely related to the new round of counterpart aid policy in Xinjiang, and second, the policy type is mainly laws and regulations, opinions, plans, methods and other documents reflecting government policies ${ }^{[3]}$, exclusion of work notices, information release and other general government documents.

\section{ANALYSIS OF THE CHARACTERISTICS OF THE FORM OF THE NEW ROUND OF POLICY ON COUNTERPART ASSISTANCE TO XINJIANG}

After collation, 128 valid samples were finalized. Analysis of the number of texts of the new round of counterpart aid policy found that 2010 is the beginning of a new round of counterpart aid work, but also the beginning of the 12th Five-Year Plan, the previous work has laid the foundation for this, the corresponding policy system has an initial plan, so with the first work conference on counterpart assistance in 2010, the number of policies reached the highest. In recent years, the number of policies promulgated in China fluctuated greatly, showing a downward trend overall. However, from 2016 to 2018 , the number of policies is in a state of growth, from 4 in 2016 to 14 in 2018, This is because with the acceleration of China's economic transformation, the future development trend must be more diversified. 2016 to 2020 is the "13th Five-Year Plan" period, in order to ensure the realization of a comprehensive well-off society on schedule. The state actively promotes the construction and planning of 165 major projects in various fields and actively exerts the vitality and creativity of various market players. Government departments at all levels have responded positively to the formulation of corresponding work plans and tasks, the Ministry of People's Social Welfare, the Ministry of human resources and social security, the Ministry of water resources, the Ministry of education and the Ministry of health have all issued notices, saying that we should do a good job in assisting Xinjiang and Tibet and implement the supporting measures. It can be seen that the state can well introduce policies around the new round of counterpart aid to Xinjiang and get response, so as to implement actions and provide guarantee for the longterm stable and sustainable development of Xinjiang.

\subsection{Policy publisher analysis}

From the perspective of the main body of the documents, according to the authoritative order, the issuing agencies of the new round of counterpart aid policies in Xinjiang mainly include the State Council, the general office of the State Council, the Central Committee of the Communist Party of China, the national development and Reform Commission, the Ministry of finance, the Ministry of education, the Ministry of health, the Ministry of agriculture and rural areas and other departments, as well as provincial and municipal governments, people's congresses and related departments. In terms of policy effectiveness, it mainly includes the normative documents of the State Council, the internal party regulations, the departmental normative documents, the departmental working documents, the team regulations, the local normative documents, the local working documents, which are more diversified; Among them, there are 6 normative documents of the State Council, 11 normative documents of departments, 2 working documents of departments, 1 law of the Party, 32 normative documents of local governments and 76 working documents of local work. Because of the hierarchical characteristics of China's administrative organizations, documents issued by higher governments and related departments are being implemented to lower government departments, forming a top-down diffusion model, and local governments and departments play an active role in proliferation, with certain agitation, and form a network structure between policies[4]. In terms of volume, the number of local regulations reached 108 , accounting for 84 per cent of the total policy text. At the same time, there is also a certain degree of diffusion between departments at the same level, for the new round of counterpart assistance policy, involving a wide range of institutions to respond to the policy is also more extensive, reflecting the comprehensive policy text, but also reflects the different functional departments in the new round of counterpart assistance in the territory play different roles.

\subsection{Analysis of the form of policy release}

Judging from the filtered policy text, the new round of policy forms mainly includes eight types of notifications, opinions, methods, plans, implementation plans, project, announcements and notices, of which the largest number of policies in the form of notifications (64), accounting for $50 \%, 22$ opinions and 18 implementation plans, respectively, accounting for $31 \%$, 9 plans, 5 methods, 4 projects and notices, respectively, and there is only one policy in the form of circulars. Different forms of policy reflect different normative and operationalities. Combined with 128 policy texts in this paper, the vast majority of them are issued in the form of notice, opinion, plan, etc., which have weak operability and are used to play a guiding role. The implementation 
plan and policy have strong operability, but there are only 19 texts in these two policy forms, accounting for $14.84 \%$. It can be seen that the new round of counterpart aid policies in Xinjiang are mostly guidance policies, less operable and normative policies, and lack of mandatory and authoritative policies.

\section{A NEW ROUND OF POLICY CONTENT ANALYSIS OF COUNTERPART ASSISTANCE TO XINJAING}

As one of the most effective methods of policy analysis, this paper uses the key words of policy text to investigate the new round of China's counterpart aid policy to Xinjiang. Key words analysis is the basic content of policy text analysis ${ }^{[5]}$. Through the statistical analysis of the key words of the policy text directly related to the new round of counterpart aid to Xinjiang, we can more objectively investigate the characteristics and laws of the new round of counterpart aid to Xinjiang. Enter 128 policy text titles into the "Tu Yue" word frequency analysis software, combined with manual annotation, extract one or two keywords representing the core content of each policy text, and a total of 83 key words are obtained. Then they are imported into the table, and the invalid key words irrelevant to the policy are removed, and some key words are combined with synonyms. In order to make the keywords more suitable for the situation and cover a more comprehensive range, only the keywords with the most frequent occurrences are selected for retention, a total of 14 keywords are listed as follows:

Table 1 High-frequency keywords in policy texts

\begin{tabular}{lclc}
\hline Words & Frequency & Words & Frequency \\
\hline selected & 21 & technology & 6 \\
teacher & 15 & finance & 5 \\
industry & 13 & education & 5 \\
project & 13 & economy & 4 \\
fund & 12 & employment & 5 \\
agriculture & 8 & health care & 3 \\
talent & 6 & poverty alleviation & 3
\end{tabular}

The above 14 key words reflect the focus and emphasis of the new round of counterpart aid policy in Xinjiang. The frequency represents the degree of attention to things, and the higher the degree, the higher the degree of attention, and vice versa. As can be seen from table 1, the word "selection" appears the most frequently, reflecting that the main mode of assistance to the new round of counterpart assistance to Xinjiang is through the input of the provinces to persons in various fields of the assisted areas, which is a form of talent assistance. It also shows that the development of a region is inseparable from the driving role of human resources. The following are teachers, industry and projects, which respectively indicate that education assistance, industrial assistance and project assistance. By improving the level of education, Xinjiang shortens the gap between the educational ability of other regions, thus improving the local employability level. Through industrial assistance to Xinjiang, attract enterprises to invest and introduce economic cooperation projects in Xinjiang, promote the transformation of economic development mode in Xinjiang to achieve fiscal revenue. Then there is "agriculture", "talent", "technology", "education" and "employment", because the industrial level in Xinjiang is lower than in other regions, so we should actively play the advantages of geographical resources to develop agriculture. "Talent" refers to the training of cadres, aiming to improve their political literacy and professional level through the training of Party and government cadres, teachers and doctors in Xinjiang. In recent years, the way of technical assistance has been increasing, bringing advanced technology, updating knowledge and information and experience in a timely manner to the assisted areas of Xinjiang, and promoting mutual assistance and cooperation between regions. In the course of implementation, the new round of counterpart assistance to Xinjiang focuses on promoting education as an important means to promote the development of Xinjiang. In addition, through employment training, the people in the assisted areas can achieve stable employment, and at the same time guide the graduates of ethnic minority colleges and universities to the Mainland for employment, and promote the transfer of employment by the masses. As a national strategy, the fight against poverty is also reflected in the counterpart aid to Xinjiang. The lower ranking of medical and health care indicates that it receives slightly lower attention, which reflects the shift in the focus of assistance to Xinjiang, the previous focus is mainly on blood transfusion, The counterpart support in the new era has changed from simple blood transfusion counterpart support to blood transfusion and blood production and heavy counterpart support ${ }^{[6]}$, which has fundamentally played an effective role in Xinjiang's economic development.

\section{CONCLUSION}

On the whole, the number and content of the new round of policy texts on counterpart assistance to Xinjiang correspond to the development trend and key work of the state and government, and adjust the policy direction and focus for the development state of Xinjiang in different periods. In addition, the main body of policy implementation is more diversified, with the continuous promotion of the policy, in addition to government agencies, the relevant organizations are also actively promoting the work of aid to Xinjiang. The field of policy assistance is also more extensive, focusing on 
education and personnel training, reflecting that the policy objective lies not only in counterpart support but also in being able to play a long-term role in effectively increasing Xinjiang's endogenous development capacity, conforming to the development of information technology, and improving the overall benefit of counterpart assistance to Xinjiang. However, from the perspective of policy release situation, the new round of counterpart aid policies in Xinjiang are not standardized enough and lack of guarantee for policy implementation. To sum up, the new round of counterpart aid policy needs to be further improved. Although the number of texts is not enough to completely describe the whole content of the new round of counterpart aid policy in Xinjiang, it has certain practical and theoretical significance for the research of the new round of counterpart aid policy in Xinjiang.

\section{PROJECT FUND}

Project of National Natural Science Foundation of China, Policy Resource Allocation and Micro entities Response--Based on The Tracking of Xinjiang Assistance Programs (71764031)

\section{REFERENCES}

[1] Chen Hong. On the Policy of Assistance to Xinjiang Since the Founding of New China. Journal of
Xinjiang Normal University (Philosophy and Social Sciences Edition), 2012, 33 (06): 58-68.

[2] Huang Zi, Ren Wei, Zhang Jian. Quantitative Study of Policy Literature: A New Direction in Public Policy Research, Journal of Public Administration, 2015, 12 (02): 129-137-158-159.

[3] Pan Dan, Tang Jing, Yang Jiaqing, Chen Wei. Evolutionary Features of China's Rural Environmental Management Policy 1978-2018 Quantitative Analysis Based on 206 Policy Texts. Journal of China Agricultural University, 2020, 25 (06): 210-222.

[4] Li Jiang, Liu Yuanhao, Huang Zi, Su Jun. Remodeling Policy Text Data Analysis with Documentary Measurement Research- Origin, Migration and Method Innovation of Policy Literature Measurements, Journal of Public Administration, 2015, 12 (02): 138-144-159.

[5] Yang Zhenglian. Methodology of The Interpretation of Public Policy Texts, 2007 (04): 143-147.

[6] Ma Yufei. 70 Years of the Founding of the People's Republic of China: The Practice, Enlightenment and Prospect of "Counterpart Support"--Take "Counterpart Assistance" as an example. Journal of liaoning Academy of Socialism, 2019 (02): 84-91. 